\title{
Determining asymmetry of roll-over shapes in prosthetic walking
}

\author{
Carolin Curtze, MSc; ${ }^{\text {* }}$ Bert Otten, PhD $;^{2}$ At L. Hof, PhD; ${ }^{1-2}$ Klaas Postema, MD, PhD ${ }^{1}$ \\ ${ }^{1}$ Department of Rehabilitation Medicine and ${ }^{2}$ Center for Human Movement Sciences, University Medical Center \\ Groningen, University of Groningen, Groningen, the Netherlands
}

\begin{abstract}
How does the inherent asymmetry of the locomotor system in people with lower-limb amputation affect the anklefoot roll-over shape of prosthetic walking? In a single-case design, we evaluated the walking patterns of six people with lower-limb amputation (3 transtibial and 3 transfemoral) and three matched nondisabled controls. We analyzed the walking patterns in terms of roll-over characteristics and spatial and temporal factors. We determined the level of asymmetry by roll-over shape comparison (root-mean-square distance) as well as differences in radius of curvature. In addition, we calculated ratios to determine spatial and temporal asymmetries and described different aspects of asymmetry of roll-over shapes. All participants showed some level of asymmetry in roll-over shape, even the nondisabled controls. Furthermore, we found good intralimb reproducibility for the group as a whole. With respect to spatial and temporal factors, the participants with transtibial amputation had a quite symmetrical gait pattern, while the gait in the participants with transfemoral amputation was more asymmetrical. The individual ankle-foot roll-over shapes provide additional insight into the marked individual adjustments occurring during the stance phase of the nondisabled limb. The two methods we present are suitable for determining asymmetry of roll-over shapes; both methods should be used complementarily.
\end{abstract}

Key words: adjustment, amputation, asymmetry, compensation strategy, foot, gait, prosthesis, radius of curvature, rollover, transfemoral, transtibial.

\section{INTRODUCTION}

While, as a rule, unimpaired walking is reasonably symmetric, walking with a prosthetic limb is characterized by a marked asymmetry of limb movements [1]. In people with lower-limb amputation, the locomotor system is inherently asymmetric in its construction, with a passive prosthetic and an active, muscle-controlled nondisabled limb. This results in multiple adjustments in gait pattern on the level of temporal dynamics (e.g., in people with transtibial amputation). The stance phase on the nondisabled limb is prolonged, while on the spatial level, the lateral stability margin of stepping is increased on the side of the prosthetic limb by placing the foot farther outside, thereby making walking with a prosthesis more stable [1]. In addition to these spatiotemporal adjustments, changes in interlimb coordination [2] as well as alterations in joint kinetics have been reported [3-4].

In the stance phase of walking, the foot rolls over the ground from heel to toe, analogous to a rolling wheel. Hansen et al. described a method for capturing the overall motion of the ankle-foot system in so-called "effective ankle-foot roll-over shapes," which form the basis of the rocker-based inverted pendulum model of walking [5]. Ankle-foot roll-over shapes are determined by transforming the successive center of pressure (COP) displacement from a laboratory-based coordinate system into a shankbased coordinate system. A remarkable invariance of these nearly circular roll-over shapes has been reported

Abbreviations: $\mathrm{COP}=$ center of pressure, RMS = root-meansquare.

*Address all correspondence to Carolin Curtze, MSc; Department of Rehabilitation Medicine, University Medical Center Groningen, Hanzeplein 1, 9713 GZ Groningen, the Netherlands; +31-50-36-18-041; fax: +31-50-36-11-708.

Email: c.curtze@umcg.nl

DOI:10.1682/JRRD.2010.08.0163 
for nondisabled subjects during walking. The literature shows that the preferred ankle-foot curvature is unaffected by shoe-heel height [6], loads carried [7], and different walking speeds [5]. Adjustments are found in the orientation of knee-ankle-foot roll-over shapes only when starting and stopping [8].

This apparent invariance of roll-over shapes, as found in nondisabled subjects, has been suggested as an "ideal” design feature for prosthetic feet [9]. Hansen et al. show that transtibial prostheses are aligned (by a prosthetist) to match as closely as possible this ideal roll-over shape [9]. Hansen et al. have also suggested that prosthetic feet should mimic the roll-over shapes of a natural foot [9-10], which they appear to do with respect to the radius of curvature when mechanically tested [11]. Hence, prosthetic feet mimicking the natural roll-over shape of a nondisabled ankle-foot system should result in a natural roll-over shape under the nondisabled limb. So far, the literature does not describe how the roll-over shape of the prosthetic limb affects the roll-over shape of the nondisabled limb in people with lower-limb amputation. To this end, we assessed the individual differences in roll-over shapes of people with transtibial and transfemoral amputation during steady-state walking. We present two methods to quantify differences in roll-over shapes: (1) based on the radius of curvature and (2) based on the quantitative coordinate comparison of the curve structures, i.e., the average distance between curves. Based on these measures, we determined the interlimb asymmetry and the intralimb reproducibility of roll-over shapes.

For a general characterization of each participant's walking patterns, we report temporal gait parameters because reference values for these characteristics are well established in the literature for all three populations [12-14].

\section{METHODS}

\section{Participants}

Six participants with amputation (three transtibial and three transfemoral) participated in the single-case design study. All participants with amputation were experienced and able walkers. They performed the test with the prostheses that they use on a daily basis. Three nondisabled participants formed the control group. All nine participants were male; Table 1 gives further participant characteristics.

\section{Apparatus}

We measured the ground reaction forces during a complete stride cycle by using two force plates (AMTI; Watertown, Massachusetts) sampling at a rate of $100 \mathrm{~Hz}$. We placed reflective markers on the lateral epicondyle of the knee and the lateral malleolus of both limbs. On the prosthetic limb, we placed the markers at the corresponding positions, allowing determination of the shank angle. An eight-camera motion capture system (Vicon; Oxford, United Kingdom) tracked the reflection markers at a sampling rate of $100 \mathrm{~Hz}$. We determined the temporal events of the gait cycle (heel-contact and toe-off) using foot switches (AURION s.r.l.; Bologna, Italy).

\section{Experimental Procedure}

We asked the participants to walk at their selfselected comfortable walking speed. We needed three trials per participant with "clean" hits (i.e., full foot support) on both force plates.

\section{Data Analysis}

We used a Woltring filter with a predicted mean square error value of 10 to filter the marker trajectories [15]. We further processed the data using MATLAB (MathWorks; Natick, Massachusetts).

\section{Ankle-Foot Roll-Over Shape}

We analyzed three stride cycles for each participant. We analyzed roll-over shapes in two dimensions, reflecting the overall walking direction. By transforming the successive COP data (from heel-contact to opposite heelcontact) from a laboratory-based into a shank-based coordinate system (Figure 1(a)-(b)), we determined the effective roll-over shapes. We set the threshold for heelcontact to one-third of body weight. We estimated the effective radius of curvature by fitting a best-fit circular arc to the transformed position data $[5,11]$. As the radius of curvature is a geometrical entity, we determined it by averaging over shape, thus giving equidistant points equal weight. We defined the origin of the shank-based coordinated system as the intersection of the extension of the shank and the floor at vertical shank angle.

\section{Comparison of Ankle-Foot Roll-Over Shapes}

We calculated the agreement between ankle-foot rollover shapes as the average distance of two curves. The curves were resampled based on the distance travelled along the curve with a step size of $1 \mathrm{~mm}$. Starting at the 
Table 1.

Participant data.

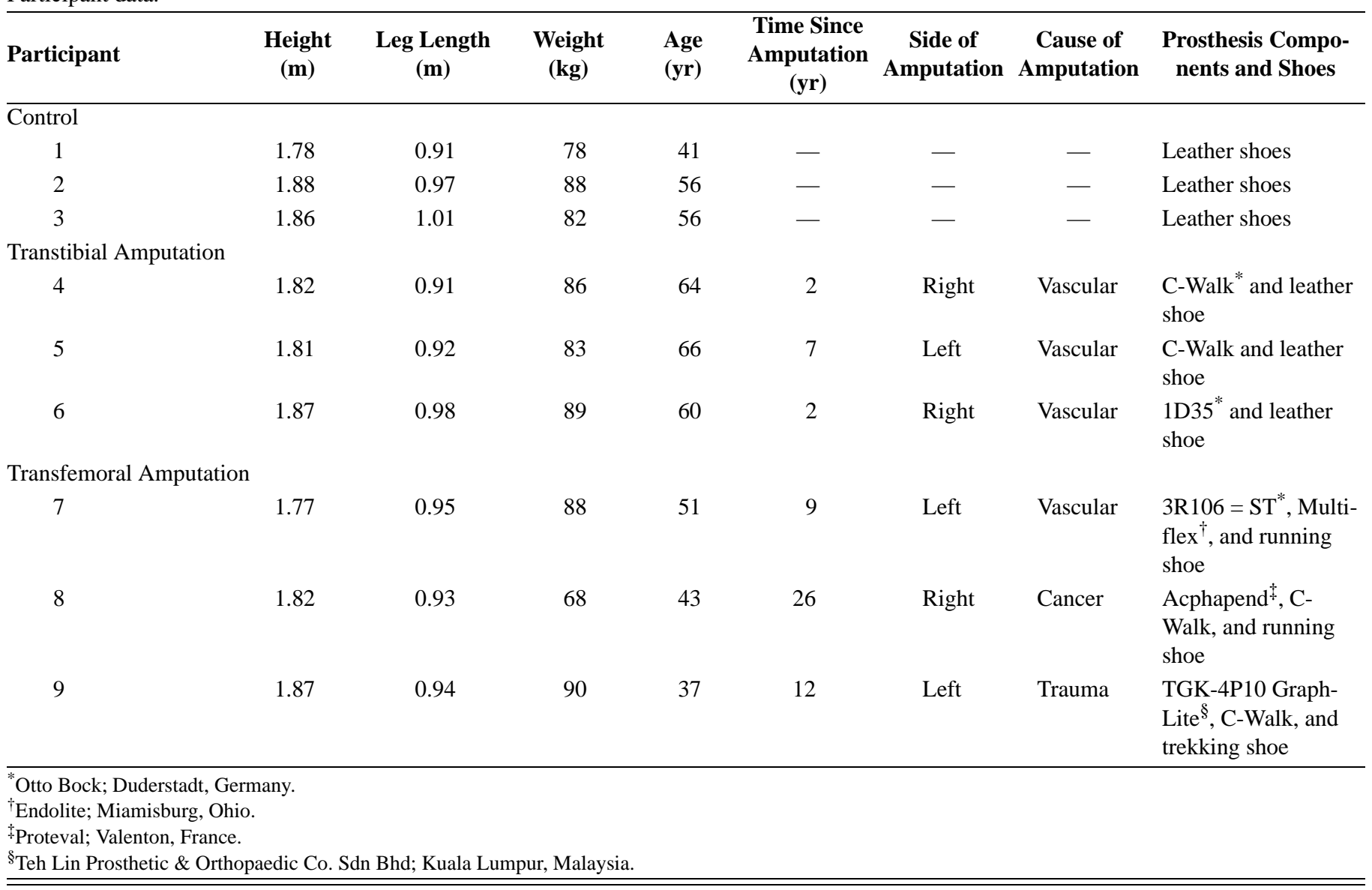

origin, the curves are resampled in the anterior and posterior directions. As each roll-over curve may have a different overall length, we compared the resampled curves over their shared length by determining the root-meansquare (RMS) distance in millimeters (Figure 1(c)).

We calculated the intralimb reproducibility, as well as the interlimb asymmetry, by comparing all three rollover shapes of a limb with one another; then we determined the mean of the average RMS distance. Similarly, we calculated the interlimb asymmetry by comparing all $3 \times 2$ roll-over shapes of the left and right or nondisabled and prosthetic limbs, resulting in 32 comparisons; finally, we determined the mean of the average RMS distance. The RMS distance is zero for identical curves, and its value increases as the two curves become more different.

\section{Spatial and Temporal Gait Characteristics}

We calculated gait velocity and stride time over a complete stride cycle. Calculated spatial and temporal parameters included step length, stance time (from heelcontact to toe-off), and double-support time (from heelcontact to opposite toe-off) for each limb. We quantified temporal gait symmetry by calculating the ratio between the mean stance time of both limbs as well as the ratio between the mean double-support time of both limbs. A ratio of 1 indicates perfect temporal symmetry.

\section{RESULTS}

The temporal asymmetry in walking appeared to increase with the level of amputation (Table 2). While each of the controls and the participants with transtibial amputation showed a relatively symmetric stance time ratio, the stance time on the nondisabled limb appeared to be prolonged in the participants with transfemoral amputation. Accordingly, the participants with transfemoral amputation showed a prolongation in double-support 
JRRD, Volume 48, Number 10, 2011
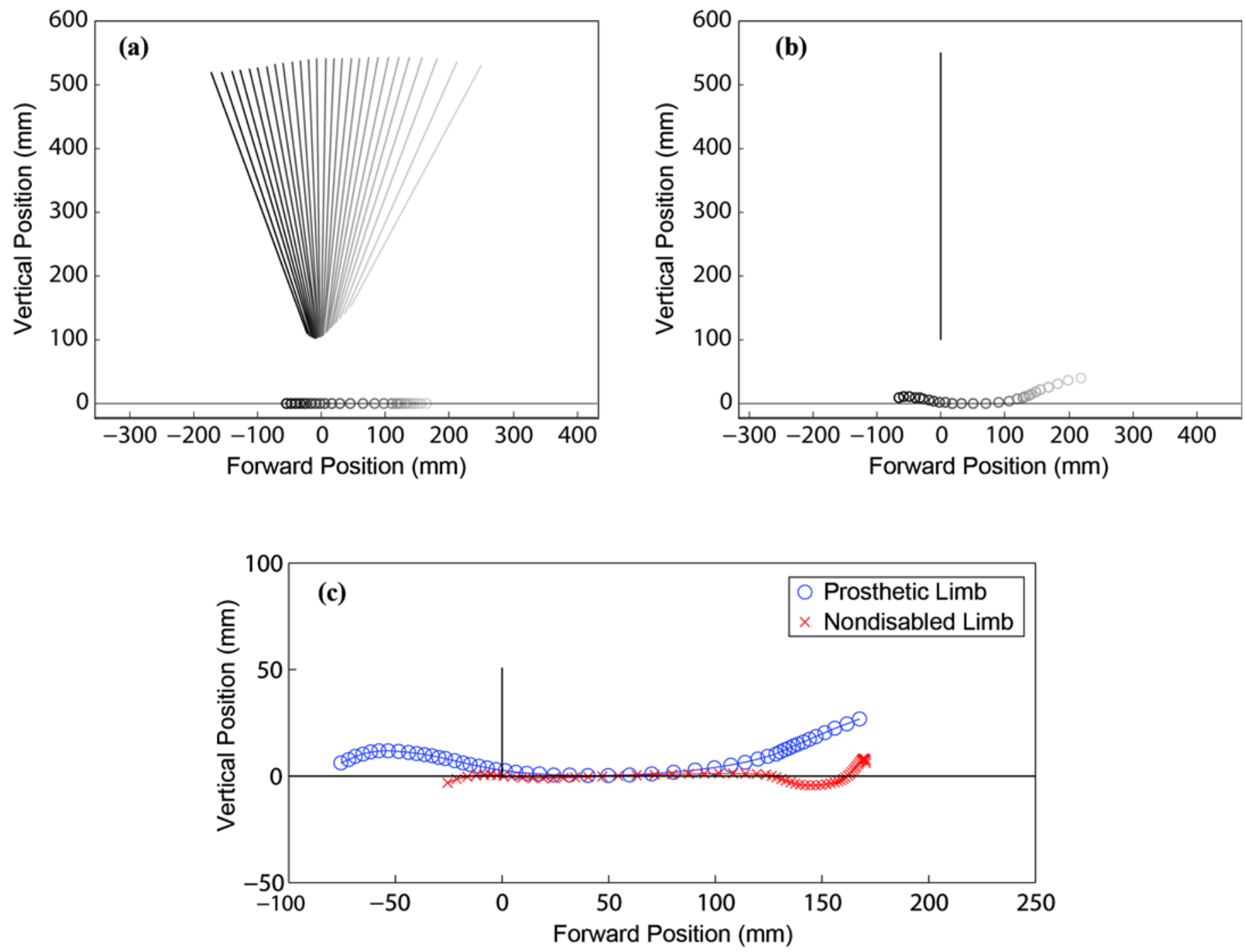

Figure 1.

Transformation of successive center of pressure data from (a) laboratory-based coordinate system into (b) shank-based coordinate system. (c) Resampled shank-based roll-over shapes to calculate root-mean-square distance between curves. Presented are roll-over shapes of nondisabled and prosthetic limbs of participant with transfemoral amputation (participant 8).

time on the prosthetic limb, while we observed no marked differences in double-support time for the participants with transtibial amputation (except for one, participant 6) or for the controls.

Figures 2 to 4 illustrate the roll-over shapes of each participant with three trials superimposed onto one another. Good intralimb reproducibility is indicated by the almost identical roll-over shapes; the three trials per limb nearly perfectly line up with one another, indicating that the overall motion of the ankle-foot system was almost identical. This good agreement is confirmed by the low RMS distance between the curves (Table 3). Comparison of the roll-over shapes between limbs, however, revealed marked differences (Figures 2-4). The RMS distances found for the between-limb comparison were larger than those found for the intralimb reproducibility (Table 3).

Interlimb comparison of the radius of curvature revealed marked asymmetries for most of the participants (Table 3). Only two of the participants with transtibial amputation (participants 4 and 6) showed symmetry with respect to radius of curvature ( 0.97 and 1.11 , respectively). 
Table 2.

Gait characteristics (mean \pm standard deviation).

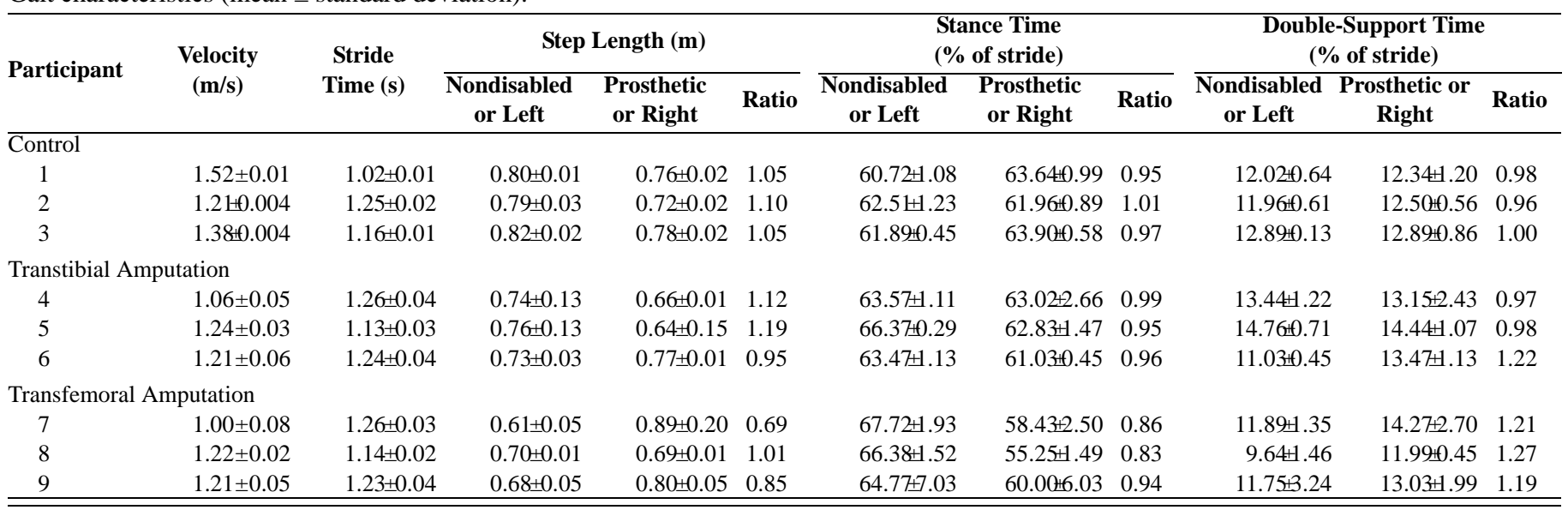

Visual inspection revealed that some roll-over shapes showed strong deviations from a circular segment (participants 8 and 9). Consequently, estimates of the radius of curvature vary considerably (Table 3 ). The differences were most prominent in participants 8 and 9, who had a high self-selected walking speed (Table 2). In order to walk fast, they pushed themselves up in the late stance phase of the nondisabled limb, thereby providing additional ground clearance for the swinging prosthetic limb. These adjustments in gait pattern are known as "vaulting." Through excessive ankle plantar flexion, the patient gains height while the rotation of the shank angle is slowed and the COP travels forward. This movement results in a flat roll-over shape, with a very large radius (low curvature). Furthermore, video analyses revealed strongly asymmetric arm movement in participant 9. In the late stance phase on the nondisabled limb, this participant pushed himself up and supported this motion by swinging the ipsilateral arm high.

Two of the participants with transfemoral amputation (participants 8 and 9) walked with the same type of prosthetic foot (Table 1). Interestingly, the resulting roll-over shapes of the prosthetic limb still differed substantially in form. This could be caused by differences in prosthesis outline and shoe model, as well as by differences in multijoint dynamics in combination with body weight differences.

The "hooks" at the beginning (participants 1 and 3) or the end (participants 2 and 5) of some of the roll-over shapes relate to a translation of the ankle with respect to the floor at the beginning or end of stance. Here, the stance limb supported more than one-third of body weight.

\section{DISCUSSION}

In this single-case design study, we showed that ankle-foot roll-over shapes in people with amputation are highly individual. Most prominent were the adjustments of roll-over shape of the nondisabled limb in the participants with transfemoral amputation. Each participant had his own unique individual roll-over shape, like a personal signature. In order to ensure ground clearance of the swinging prosthetic limb, some participants with transfemoral amputation lifted and pushed themselves up in late stance [12]. Because of the passive properties of the prosthetic system, all compensations need to be made by the nondisabled limb [16]. In steady-state walking, the roll-over shape of the prosthetic limb will be about the same in every step. The roll-over shape in the nondisabled limb can be actively adjusted to the limitations of a particular prosthetic limb. These adjustments were different but very repeatable in each participant, indicating that they had all established a steady gait pattern. In the participants with transtibial amputation, we also found some interlimb differences; these were, however, considerably smaller.

Interestingly, even though the roll-over shapes generated during the stance phase of the prosthetic limb are comparable with those found in nondisabled controls, the participants with transfemoral amputation still adjusted their roll-over shape on the side of the nondisabled limb. The three participants with transtibial amputation, however, appeared to benefit from the "natural" roll-over shape of the prosthetic limb. The radius of curvature in the prosthetic limb fell within the range of control values. The radii of the prosthetic limbs appeared to range 
Left Limb
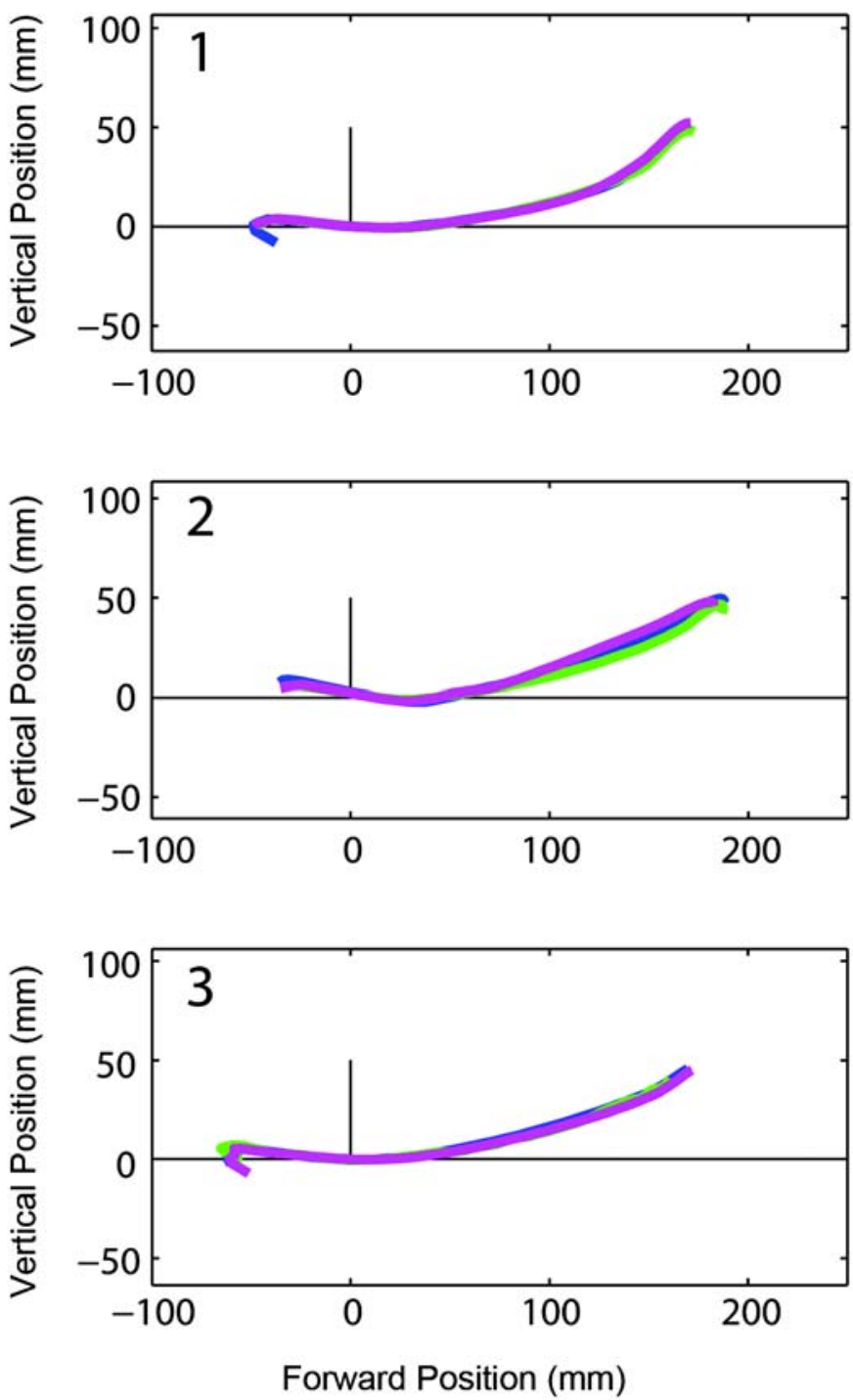

Right Limb
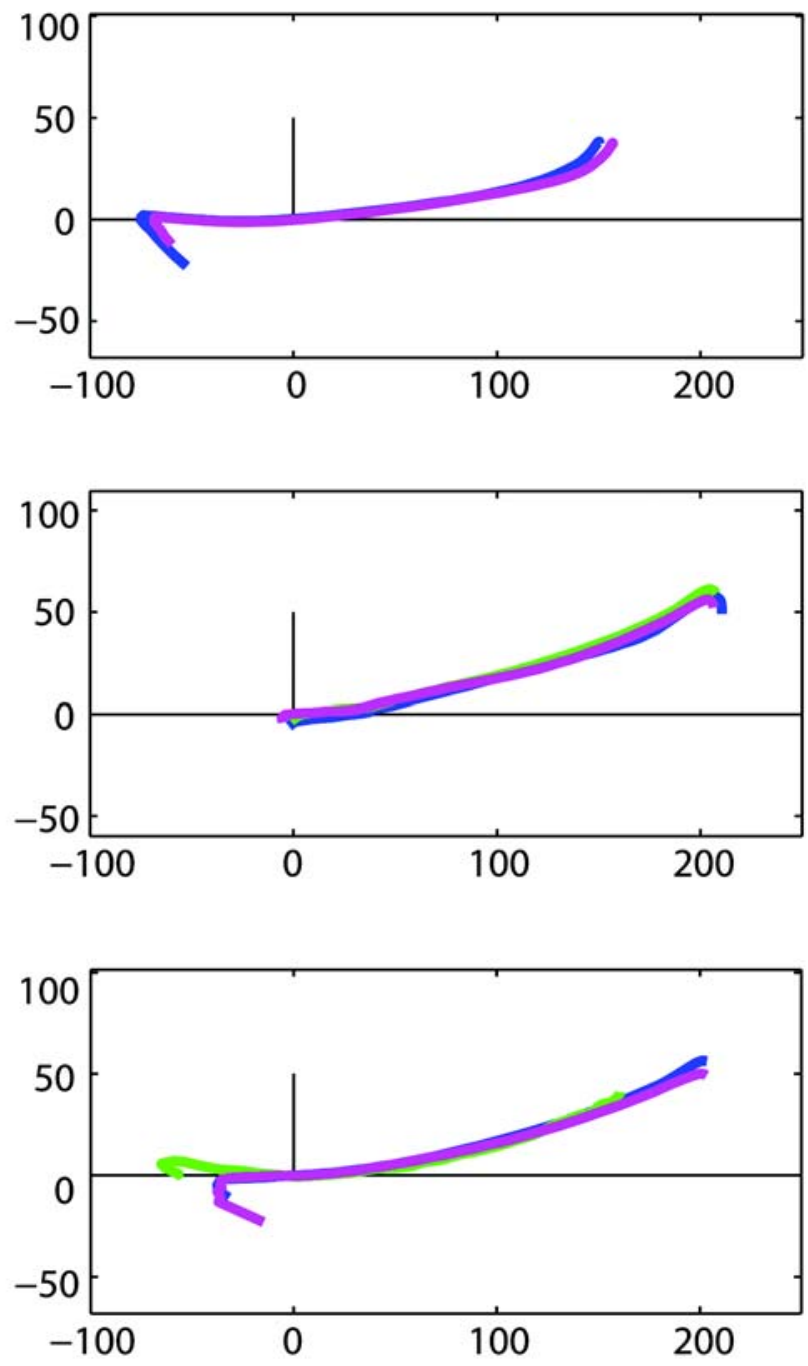

Forward Position (mm)

Figure 2.

Roll-over shapes of three trials (indicated by separate colors) for left and right limbs in nondisabled controls (participants 1-3).

between 30 and 43 percent of the leg length. Depending on the relative radius of curvature, a prosthetic foot can be considered as more or less stable [11]. Previous research shows that nondisabled people walk with curvatures of about 30 percent of the leg length [5,17]. In combination with the remaining knee function in the amputated limb, this natural roll-over shape of the prosthetic limb allows people to achieve a symmetric walking pattern. The participants with transtiabial amputation showed little signs of adjustment in the nondisabled limb, which had a more or less natural circular ankle-foot roll-over shape.
With respect to the interlimb differences, the three controls did show a less symmetric roll-over shape than expected. These high interlimb differences in the controls may be caused by functional gait asymmetry, where the nondominant limb contributes more to support. The dominant limb is thought to contribute more to the push-off during propulsion [18], which might be reflected in a more flattened roll-over shape. All three controls indicated their right limb as dominant, which agrees with the larger radii found for this side. This potential relation deserves further investigation in a larger population. 

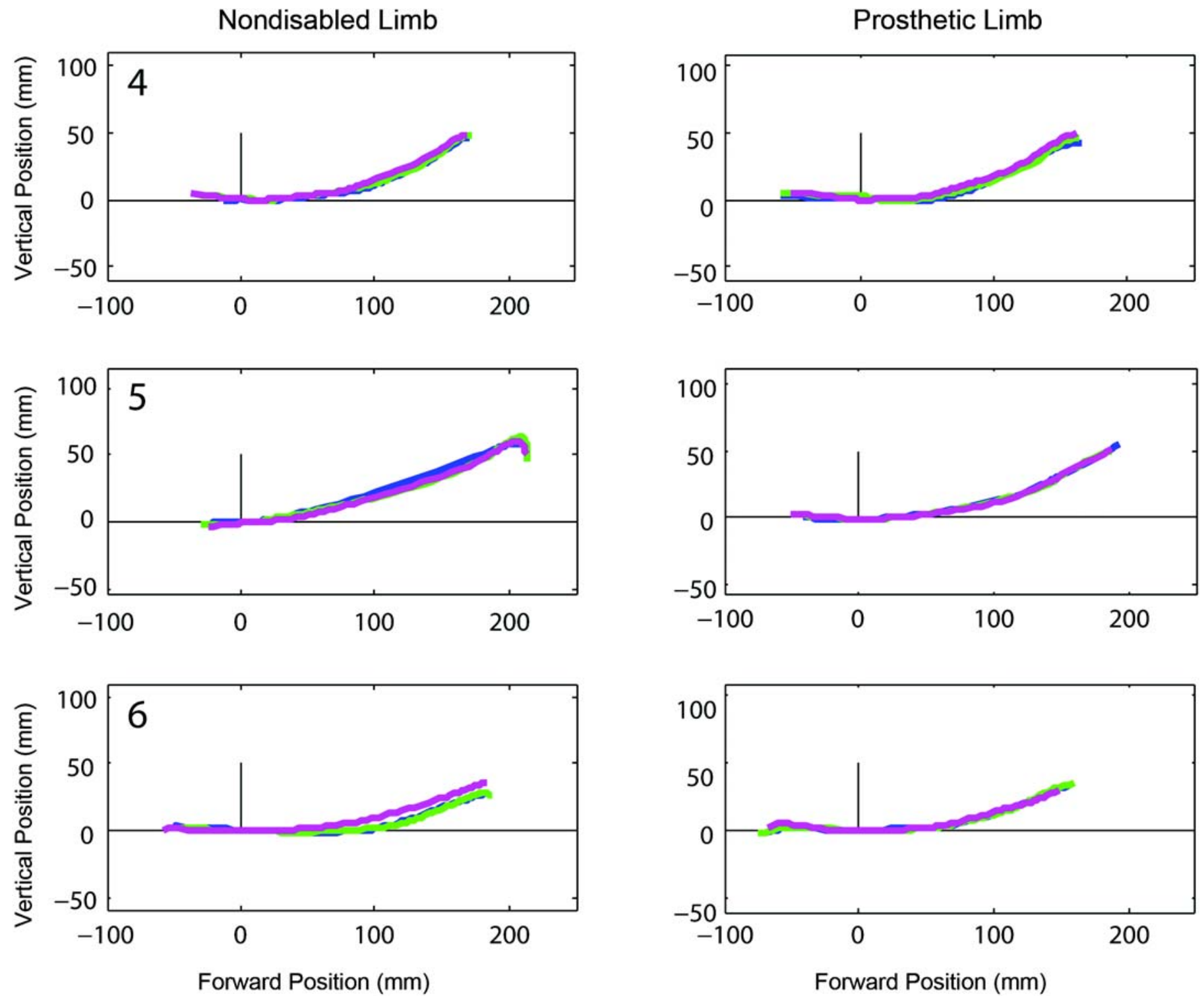

Figure 3.

Roll-over shapes of three trials (indicated by separate colors) for nondisabled and prosthetic limbs in participants with transtibial amputation (participants 4-6).

Finally, note that determining the radius of curvature by fitting a circular arc to roll-over shapes has its limitations. When applying this method, roll-over shapes are assumed to be circular. However, as the cases presented here illustrate nicely, this assumption is not satisfied in all cases. The method is very sensitive to any deviations from circular, strongly affecting the estimation of the radius of curvature. Furthermore, this is reflected in a decrease of the coefficient of determination $\left(R^{2}\right)$, a measure for how well the data are predicted by the model. In this study, we determined the radius of curvature by averaging over shape, hereby giving equidistant points equal weight. When nonresampled time data would have been used, regions where the COP changes little with time (at initial and final stance) would have received even more weight. For not strictly circular roll-over patterns, this leads to strong deviations in the estimation of the radius. Nevertheless, radii found for shapes with a close-to-circular 

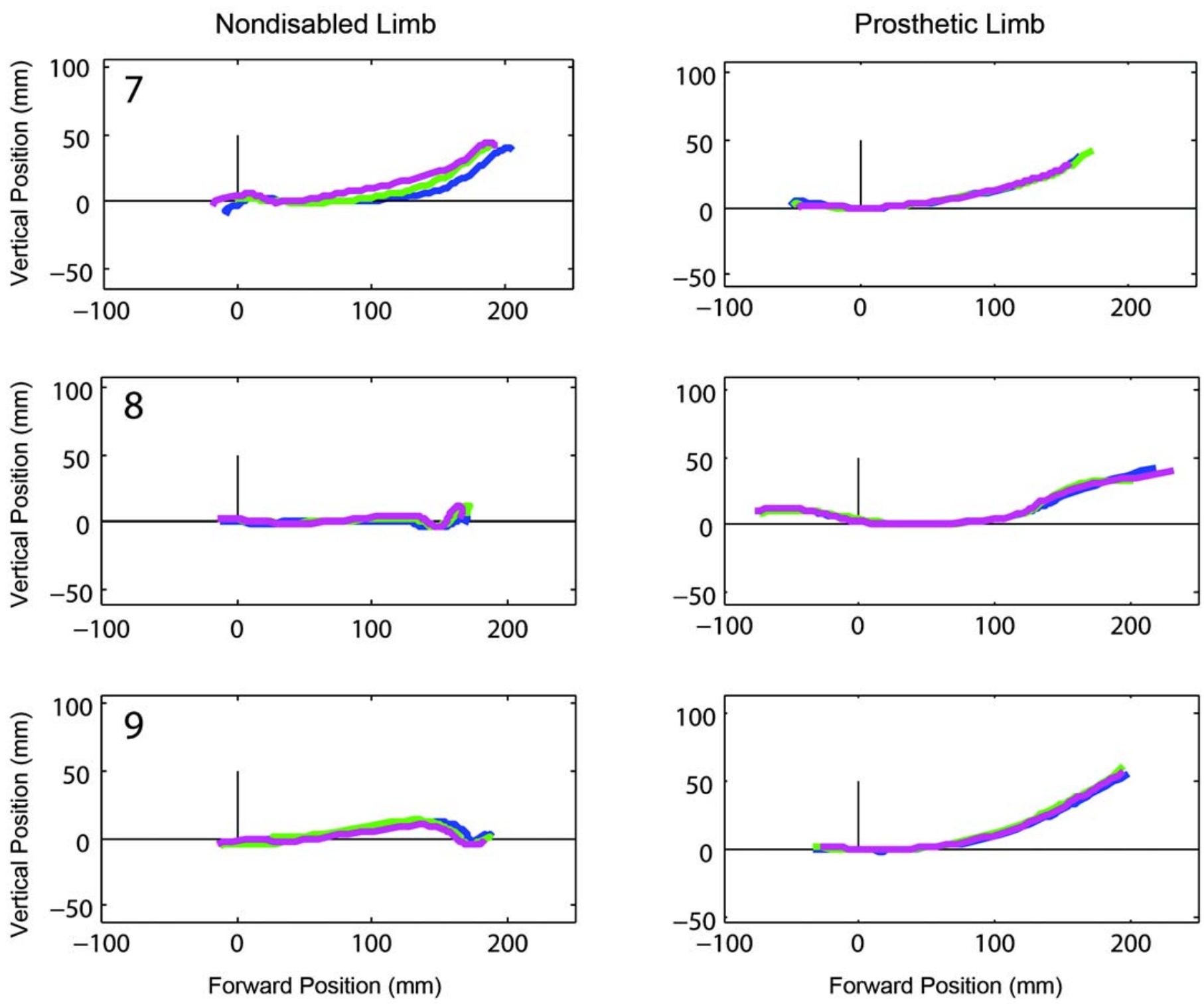

Figure 4.

Roll-over shapes of three trials (indicated by separate colors) for nondisabled and prosthetic limbs in participants with transfemoral amputation (participants 7-9).

shape were approximately 30 to 50 percent of the leg length, a range that was found to be metabolically optimal in nondisabled people [19].

In cases where the assumption of circularity of the roll-over shape is violated, statistical testing for differences in radius of curvature between limbs and subjects appears inappropriate. Rather, analyses should aim toward discussing the individual adjustments of such cases.

When determining asymmetry of roll-over shapes by means of radius of curvature, we should note that this measure is sensitive to deviations from circular shape, while when using the RMS distance, the outcome is sensitive to shift between curves. Consequently, when comparing two identical curves, the RMS distance can deviate from zero in case these curves are shifted. However, two curves can be different in shape although they have the same best-fit radius of curvature. Because both measures highlight different aspects of asymmetry, they should be used complementarily instead of interchangeably. 
Table 3.

Roll-over shape characteristics.

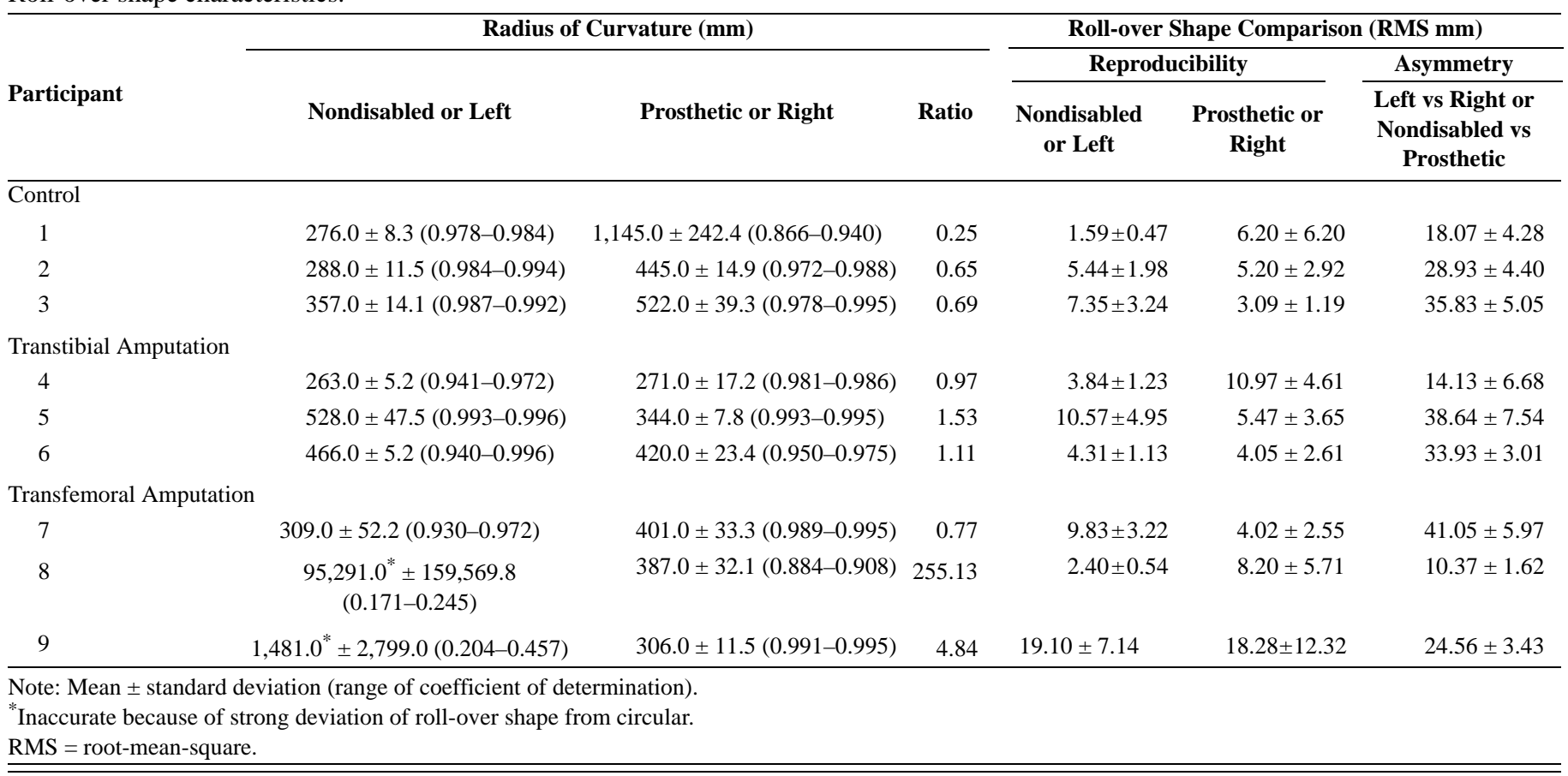

The analyses of temporal gait dynamics revealed a typical prolonged stance phase on the nondisabled limb in participants with transfemoral amputation. This asymmetry in stance phase agrees with the findings of previous studies $[1,16]$. In the participants with transtibial amputation, this asymmetry was also present but less distinct [13]. Additionally, we found this asymmetry to be strongly influenced by the level of amputation. The three participants with transtibial amputation had a much more symmetric stance phase ratio than the three participants with transfemoral amputation. Another characteristic finding is the prolongation of the double-support phase for the prosthetic limb in participants with transfemoral amputation [16], which can be considered to increase stability during stance on the prosthetic limb. Again, the participants with transtibial amputation did not show this adjustment but had a quite symmetric double-support phase. It appears that both adjustments, the prolonged stance on the nondisabled limb and the prolonged double-support phase on the prosthetic limb, correlate with the level of amputation. The loss of the natural knee joint and resulting absence of direct muscular joint control in participants with transfemoral amputation appear to be critical for an increase in stabilizing adjustments. However, we present the individual temporal gait characteris- tics purely to indicate that these cases are within the normal range of people with amputation.

Limitations of this study are the small study group size and the limited number of walking trials per participant. However, despite the small sample size, the results show that roll-over shapes deviate from a circular shape as an effect of adjustments in the nondisabled limb, thereby violating the generally assumed circularity [5-9]. Future research on roll-over shapes in prosthetics should give more attention to this aspect.

\section{CONCLUSIONS}

Patients with amputation often desire a symmetric gait pattern, and determining roll-over shape can help identify asymmetries. However, the amputation locomotor system is inherently asymmetric, and strong arguments exist against reestablishing a symmetric gait pattern without considering the functional consequences. Determining roll-over shape might eventually help us better understand adjustment strategies in prosthetic walking and achieve an optimal compromise for each individual patient. 


\section{ACKNOWLEDGMENTS}

\section{Author Contributions:}

Study concept and design: C. Curtze, B. Otten, A. L. Hof, K. Postema. Acquisition of data: C. Curtze.

Analysis and interpretation of data: C. Curtze, B. Otten, A. L. Hof,

K. Postema.

Drafting of manuscript: C. Curtze.

Critical revision of manuscript for important intellectual content:

B. Otten, A. L. Hof, K. Postema.

Study supervision: B. Otten, A. L. Hof, K. Postema.

Financial Disclosures: The authors have declared that no competing interests exist.

Funding/Support: This material was unfunded at the time of manuscript preparation.

Additional Contributions: The authors thank Henk Zijlstra for inspiring this research project, Ronald Davidsz for his assistance with data collection, and Rainer Breitling for his helpful comments on the manuscript.

Institutional Review: The medical ethics committee of the University Medical Center Groningen approved the study protocol. All participants gave their informed consent.

Participant Follow-Up: The authors do not plan to inform participants of the publication of this study.

\section{REFERENCES}

1. Hof AL, Van Bockel RM, Schoppen T, Postema K. Control of lateral balance in walking. Experimental findings in normal subjects and above-knee amputees. Gait Posture. 2007; 25(2):250-58. [PMID: 16740390] http://dx.doi.org/10.1016/j.gaitpost.2006.04.013

2. Donker SF, Beek PJ. Interlimb coordination in prosthetic walking: Effects of asymmetry and walking velocity. Acta Psychol (Amst). 2002;110(2-3):265-88. [PMID: 12102109] http://dx.doi.org/10.1016/S0001-6918(02)00037-9

3. Beyaert C, Grumillier C, Martinet N, Paysant J, André JM. Compensatory mechanism involving the knee joint of the intact limb during gait in unilateral below-knee amputees. Gait Posture. 2008;28(2):278-84. [PMID: 18205487] http://dx.doi.org/10.1016/j.gaitpost.2007.12.073

4. Silverman AK, Fey NP, Portillo A, Walden JG, Bosker G, Neptune RR. Compensatory mechanisms in below-knee amputee gait in response to increasing steady-state walking speeds. Gait Posture. 2008;28(4):602-9. [PMID: 18514526] http://dx.doi.org/10.1016/j.gaitpost.2008.04.005

5. Hansen AH, Childress DS, Knox EH. Roll-over shapes of human locomotor systems: Effects of walking speed. Clin Biomech (Bristol, Avon). 2004;19(4):407-14.

[PMID: 15109762] http://dx.doi.org/10.1016/j.clinbiomech.2003.12.001

6. Hansen AH, Childress DS. Effects of shoe heel height on biologic rollover characteristics during walking. J Rehabil
Res Dev. 2004;41(4):547-54. [PMID: 15558383]

http://dx.doi.org/10.1682/JRRD.2003.06.0098

7. Hansen AH, Childress DS. Effects of adding weight to the torso on roll-over characteristics of walking. J Rehabil Res Dev. 2005;42(3):381-90. [PMID: 16187250]

http://dx.doi.org/10.1682/JRRD.2004.04.0048

8. Miff SC, Hansen AH, Childress DS, Gard SA, Meier MR. Roll-over shapes of the able-bodied knee-ankle-foot system during gait initiation, steady-state walking, and gait termination. Gait Posture. 2008;27(2):316-22.

[PMID: 17544273]

http://dx.doi.org/10.1016/j.gaitpost.2007.04.011

9. Hansen AH, Meier MR, Sam M, Childress DS, Edwards ML. Alignment of trans-tibial prostheses based on roll-over shape principles. Prosthet Orthot Int. 2003;27(2):89-99.

[PMID: 14571938]

http://dx.doi.org/10.1080/03093640308726664

10. Hansen AH, Childress DS, Knox EH. Prosthetic foot rollover shapes with implications for alignment of trans-tibial prostheses. Prosthet Orthot Int. 2000;24(3):205-15.

[PMID: 11195355]

http://dx.doi.org/10.1080/03093640008726549

11. Curtze C, Hof AL, Van Keeken HG, Halbertsma JP, Postema K, Otten B. Comparative roll-over analysis of prosthetic feet. J Biomech. 2009;42(11):1746-53.

[PMID: 19446814$]$

http://dx.doi.org/10.1016/j.jbiomech.2009.04.009

12. Van der Linden ML, Solomonidis SE, Spence WD, Li N, Paul JP. A methodology for studying the effects of various types of prosthetic feet on the biomechanics of trans-femoral amputee gait. J Biomech. 1999;32(9):877-89.

[PMID: 10460124$]$ http://dx.doi.org/10.1016/S0021-9290(99)00086-X

13. Vanicek N, Strike S, McNaughton L, Polman R. Gait patterns in transtibial amputee fallers vs. non-fallers: Biomechanical differences during level walking. Gait Posture. 2009;29(3):415-20. [PMID: 19071021] http://dx.doi.org/10.1016/j.gaitpost.2008.10.062

14. Lamoth CJ, Ainsworth E, Polomski W, Houdijk H. Variability and stability analysis of walking of transfemoral amputees. Med Eng Phys. 2010;32(9):1009-14.

[PMID: 20685147] http://dx.doi.org/10.1016/j.medengphy.2010.07.001

15. Woltring $H$. On optimal smoothing and derivative estimation from noisy displacement data in biomechanics. Human Move Sci. 1985;4(3):229-45. http://dx.doi.org/10.1016/0167-9457(85)90004-1

16. Schmid M, Beltrami G, Zambarbieri D, Verni G. Centre of pressure displacements in trans-femoral amputees during gait. Gait Posture. 2005;21(3):255-62. [PMID: 15760740] http://dx.doi.org/10.1016/j.gaitpost.2004.01.016 
17. McGeer T. Passive dynamic walking. Int J Robot Res. 1990; 9:62-82. http://dx.doi.org/10.1177/027836499000900206

18. Sadeghi H, Allard P, Duhaime M. Functional gait asymmetry in able-bodied subjects. Hum Move Sci. 1997;16(2-3): 243-58. http://dx.doi.org/10.1016/S0167-9457(96)00054-1

19. Adamczyk PG, Collins SH, Kuo AD. The advantages of a rolling foot in human walking. J Exp Biol 2006;209(Pt 20):3953-63. [PMID: 17023589]

http://dx.doi.org/10.1242/jeb.02455

Submitted for publication August 30, 2010. Accepted in revised form May 9, 2011.
This article and any supplementary material should be cited as follows:

Curtze C, Otten B, Hof AL, Postema K. Determining asymmetry of roll-over shapes in prosthetic walking. J Rehabil Res Dev. 2011;48(10):1249-60.

DOI:10.1682/JRRD.2010.08.0163

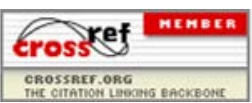


